\title{
Antonio Candido e Mário de Andrade (anotações preliminares)
}

\author{
Edu Teruki Otsuka*
}

\section{RESUMO}

Embora geralmente reconhecida, a importância do pensamento e do exemplo de Mário de Andrade como teórico e crítico para o desenvolvimento das concepções de Antonio Candido ainda não foi objeto de investigação sistemática, com mapeamento de paralelos, afinidades e divergências nas ideias e na orientação. Neste artigo, procuro examinar alguns pontos de contato em textos dos dois intelectuais, tomando como eixo o debate sobre "arte livre" e "arte participante" dos anos 1940 no Brasil, e destacando a centralidade da noção de técnica na reflexão de Mário de Andrade sobre a função social da arte.

Palavras-chave: Antonio Candido. Mário de Andrade. Crítica literária. Autonomia e engajamento.

* Professor do Departamento de Teoria Literária e Literatura Comparada da Faculdade de Filosofia, Letras e Ciências Humanas (USP). 


\title{
Antonio Candido and Mário de Andrade (Preliminary Notes)
}

\begin{abstract}
Although generally aknowledged, the influence of critic and theorist Mario de Andrade's thought and representativeness in the development of Antonio Candido's ideas has not been submitted to a thorough examination, concerning similarity and diversity in their conceptions and critical orientation. In this paper, I explore converging moments in both critics' works, considering the 1940s debate on "free art" and "committed art" in Brazil, and emphasizing the centrality of the notion of tecnique in Andrade's reflection on the social function of art.
\end{abstract}

Keywords: Antonio Candido. Mário de Andrade. Literary criticism. Autonomy and commitment. 
1.

Em 1943, Antonio Candido, então crítico de livros na Folha da manhã, escreveu dois rodapés - "Jornada heroica" e "Artista e sociedade" - a propósito do aparecimento de $\mathbf{O}$ baile das quatro artes, de Mário de Andrade, que pouco antes havia publicado também Aspectos da literatura brasileira. Nesses artigos, mais do que resenhar o volume, Candido procurava descrever o percurso das ideias do escritor que, chegando aos 50 anos de idade, tornava patente, com a reunião daqueles escritos, uma reorientação de suas ideias e conduta, resultante de uma "jornada heroica" em busca de maior sistematização de seu pensamento estético-político e de uma tentativa de superar os impasses que atravessavam sua obra de pesquisador, crítico e teórico da arte e da cultura. ${ }^{1} \mathbf{O}$ baile das quatro artes reunia estudos sobre música, pintura, cinema e literatura, abordando questões centrais de seu pensamento, sobretudo no que diz respeito à técnica.

O problema da técnica artística é o fio que une os estudos do livro, sendo tratado mais extensamente em "O artista e o artesão", aula inaugural do curso de Filosofia e História da Arte que Mário de Andrade havia ministrado na Universidade do Distrito Federal em 1938. Como se sabe, nesse texto, Mário apresenta uma concepção abrangente de técnica, diferenciando nela três dimensões: o artesanato, a parte ensinável da técnica, que abarca o aprendizado do material e suas exigências; o virtuosismo, que envolve o conhecimento abalizado da tradição,

1 Em seu último ano de vida, Mário de Andrade ainda ensaiaria nova exposição organizada de suas ideias sobre o engajamento do artista e a função política da arte na série "O banquete", deixada incompleta (ANDRADE, 1977). 
o domínio das diferentes técnicas históricas; e a técnica pessoal, a parte mais importante, que consiste na solução pessoal do artista no fazer da obra de arte - solução que, sendo resultado da relação entre o artista e o material, entre a liberdade ilimitada da criação e as limitações impostas pela matéria, implica também o enfrentamento, pelo artista, dos problemas específicos de seu tempo. É por meio da aquisição de uma consciência técnica disciplinada que o artista define sua atitude diante da vida e alcança a solução pessoal para objetivar e concretizar uma "verdade interior" (ANDRADE, 1975a; LAFETÁ, 2000). Assim, Mário considera imprescindível, para o artista, "adquirir uma severa consciência artística que o... moralize". (ANDRADE, 1975a, p. 27), pois, como afirma em "Atualidade de Chopin", é na dedicação intransigente à obra de arte que o artista se torna "o revoltado por excelência contra os defeitos e as feiúras da vida, contra as injustiças, as falsificações, contra as mentiras sociais, as desgraças todas". (ANDRADE, 1975a, p. 146).

Arecepção imediata de $\mathbf{O}$ baile das quatro artes na imprensa causou desgosto a Mário de Andrade, na medida em que alguns dos comentadores demonstravam incompreensão de suas ideias - fato tanto mais consternador porque a incompreensão, que parecia implicância, vinha de intelectuais que acompanhavam o trabalho de Mário há tempos. Foi o que sucedeu com o artigo de Sérgio Milliet, que, contestando o uso que Mário fazia das noções de artesanato e técnica em "O artista e o artesão", propõe a substituição de "técnica pessoal" por "estilo" (MILLIET, 1943a; COLI, 1998), mas sem que essa proposta trouxesse de fato maior precisão e rigor terminológico. Não discutirei aqui o teor da polêmica - que foi detalhadamente reconstituída e comentada por Jorge Coli (1998) -, mas menciono-a apenas 
para indicar que a discussão demonstrava que o texto de Mário, aparentemente vago em suas definições, não foi compreendido como o esforço de sistematização que era. Mário sentiuse forçado a escrever uma resposta, por meio de artigo na imprensa, procurando esclarecer suas noções, e acusa Milliet de negar-lhe "o direito de conceituar a terminologia de um corpo orgânico de ideias estéticas que venho me esforçando por obter”. (ANDRADE, 1943, p. 9; COLI, 1998, p. 48). No mesmo jornal e no mesmo dia em que apareceu a resposta de Mário a Milliet, publicou-se na página ao lado um artigo de Luís Martins (1943; COLI, 1998), que em parte acompanhava Milliet; também aqui, verificava-se a persistência de um mal-entendido quanto à noção de artesanato, ainda que, anos antes, Mário já houvesse discutido o assunto com Martins (ANDRADE, 1963). Por sua vez, Milliet voltou a abordar o problema de terminologia e, sem dar o braço a torcer, prefere encerrar a discussão por considerar infindável o debate (MILLIET, 1943b; COLI, 1998). Por fim, Mário chegou a esboçar nova resposta, que não publicou, mas ainda deixaria escapar uma farpa contra Milliet no artigo sobre Fogo morto, seis meses depois (ANDRADE, 1972).

Tendo em vista essas confusões que "O artista e o artesão" acabou gerando em alguns leitores, os rodapés de Antonio Candido se destacam pelo rigor com que discute as ideias e pela argúcia na reconstituição do percurso realizado por Mário de Andrade. Que o próprio Mário tenha tomado os artigos de Candido como uma explicação adequada de suas ideias não se deve apenas ao fato de o jovem crítico traduzir seu pensamento com fidelidade, mas também porque Candido demonstra ter compreendido o longo processo de reflexão e apuro conceitual de Mário, apreendendo as consequências teóricas do percurso, que envolvem as implicações sociais da aquisição da consciência 
técnica, pela qual Mário batalhava.

Com efeito, na compreensão do próprio Mário de Andrade, a aula de 1938 recolhia e organizava reflexões anteriores e, principalmente, abria um ciclo de reflexões que ele chamou, em carta de 1944 a Carlos Lacerda, de "fase reconstrutiva" (ANDRADE, 1963, p. 92), anunciada em "Cultura musical (oração de paraninfo)" (ANDRADE, 1975b), de 1935, e desenvolvida nos escritos mais recentes. Em carta a Henriqueta Lisboa, Mário esclarece que a questão tratada em "O artista e o artesão", ou seja, "a influência moralizadora do artesanato, da técnica no grande sentido, [...] foi a declaração de guerra que produziu [...] o 'Movimento Modernista', a 'Elegia de Abril', a 'Atualidade de Chopin' e enfim explodiu no Café como criação". (ANDRADE, 2010, p. 257).

Nos rodapés sobre $\mathbf{O}$ baile das quatro artes, Antonio Candido identifica uma recomposição na atitude de Mário diante da vida e procura dar a ver o fio mais ou menos oculto que liga seus escritos da última fase. Após indicar que algo da nova atitude de Mário já se fazia pressentir no Ensaio sobre a música brasileira (1928), Candido apresenta um roteiro do pensamento de Mário que, partindo de "O artista e o artesão" (1938), passa pela articulação com outros textos do livro e desemboca em "O Movimento Modernista" (1942). Tomando a reflexão sobre o artesanato e a técnica como eixo de $\mathbf{O}$ baile das quatro artes, Candido procura indicar a unidade interna do livro, assim resumindo o caminho percorrido pelo autor:

[Mário de Andrade] parte da afirmação de que o artesanato é base para a realização integral do artista, que se eleva graças a ele a uma técnica apropriada. Mas o exagero do artesanato, isto é, o requinte técnico, leva ao virtuosismo, que pode comprometer a obra de arte, 
uma vez que lhe sobrepõe o próprio artista como objeto. Este virtuosismo, produtor de hiperindividualismo, desliga o indivíduo da realidade humana (social) que lhe compete exprimir e lhe serve de alicerce, e a arte passa a correr o perigo de se desfuncionalizar - o artista perdendo contacto com o seu tempo e os temas que ele lhe propõe. A solução está em apreender o sentido da sua época e adaptar a ele os meios técnicos, a fim de que a obra se revista de uma larga e fecunda utilidade, que sirva de apoio aos que a ela se dirigem. E o artista, assim, pode deixar de ser um criador mais ou menos gratuito para adquirir uma eficiência real, que lhe dê razão de ser em momentos como o nosso, em que todo virtuosismo se torna uma traição. (CANDIDO, 1943c, p. 5).

Os artigos de Antonio Candido procuram salientar como as concepções de Mário sobre a técnica buscam combater o individualismo excessivo, que se apresenta como "um processo dessocializante", podendo promover desorientação; a aquisição da técnica, ao contrário, liga o artista aos problemas da coletividade por meio do próprio fazer artístico. Por isso, Candido considera que a ideia, apresentada por Mário, de que "em arte, o que existe de principal é a obra de arte" orienta todo o seu pensamento estético. Candido apresenta as articulações entre artista, obra e sociedade segundo Mário de Andrade da seguinte maneira:

O contacto com os meios materiais de produção artística; o trabalho de coordená-los no processo de artefazer liga o artista à técnica do seu tempo, ou seja, a todo um aspecto da cultura deste. Se o impulso criador da inspiração é às vezes (quase sempre) a força que mais tende a segregar o artista da comunidade dos seus semelhantes [...], a técnica e os processos artesanais são a força que tendem a ligá-lo ao conjunto dos seus companheiros, aos seus problemas corporativos, às suas soluções materiais. Através desta ligação ele vai 
se aproximar das soluções sociais, vai encontrar o seu tempo e participar da sua atividade criadora. [...] Ora, esta ligação determina o caráter objetivo da sua atividade; coloca necessariamente a obra de arte, e não o próprio artista, como objeto da criação. (CANDIDO, 1943a, p. 5).

Em virtude da "força de integração grupal" da técnica, continua Candido, "o artista ganha consciência dos seus propósitos e [...] adquire uma atitude em face da vida", isto é, torna-se consciente dos valores que cria e, a partir deles, organiza uma conduta que pode conduzir tanto à integração ao grupo quanto a uma atitude inconformada "de quem propõe contra uma aparência social fictícia, apodrecente, as profundas aspirações grupais”. (CANDIDO, 1943a, p. 5). Dito de outro modo, o enfrentamento consequente dos materiais que o artista elabora jamais seria uma solução individualista, porque implica o domínio das técnicas que o ligam à coletividade, podendo conduzir ao desenvolvimento de uma técnica pessoal com que o artista expressa a "sua" verdade (como diz Mário), a qual pode traduzir uma atitude de inconformismo, impulsionada por aspirações coletivas.

Por isso mesmo, em "A elegia de abril”, de 1941, Mário de Andrade afirmaria sua confiança "na potência moralizadora da técnica", pois, para ele, é no compromisso inflexível com a técnica que se define a orientação de uma conduta, afastando o artista e o intelectual de quaisquer formas de conformismo: "se o intelectual for um verdadeiro técnico da sua inteligência, ele não será jamais um conformista". (ANDRADE, 1974, p. 193).

A questão de fundo que atravessa a reflexão de Mário de Andrade naqueles anos envolve a tensão entre a "arte desinteressada" e a "arte utilitária", implicando o problema da participação política do artista e da obra de arte. Também em 
sua atividade nos rodapés, Antonio Candido discutiria o tema do engajamento do intelectual ao definir suas linhas de orientação crítica.

2

Em "Ouverture", artigo de abertura do rodapé "Notas de crítica literária" na Folha da manhã, publicado em janeiro de 1943, Antonio Candido apresenta alguns princípios que norteariam sua atividade como crítico, ressaltando seu intuito de estudar as obras tendo em vista as "relações que a[s] prendem ao seu momento". Posicionando-se contra a atitude impressionista, que toma a obra como ponto de partida para "uma série de variações pessoais" e, desse modo, faz da crítica "uma aventura da personalidade, [...] com o intuito exclusivo de penetração e de enriquecimento pessoal", Candido considera que a tarefa do crítico seria antes a de "integrar a significação de uma obra no seu momento cultural", ou seja, apreender as ligações da obra com o tempo presente, buscando identificar nela elementos que contribuíssem para explicar sua época e, desse modo, extrair dela "uma orientação para a conduta". (CANDIDO, 2002, p. 25 26). Como apoio a essa diretriz geral, Candido argumenta que ao crítico caberia assumir o papel que lhe impõe seu tempo e, entendendo que o momento solicita o interesse pelas questões políticas, cita a observação de Mário de Andrade, feita ao final da conferência sobre o Movimento Modernista, segundo a qual “Nunca jamais ele (o homem) foi tão 'momentâneo' como agora”. (ANDRADE, 1974, p. 255). Assim, Candido assumia, como obrigação do intelectual, "o esforço para esclarecer os acontecimentos presentes" (CANDIDO, 2002, p. 28), admitindo, 
por isso mesmo, o caráter circunstancial e transitório de seus textos no jornal. Como se vê, Candido se propunha fazer uma crítica participante, que, atuando em âmbito distinto da atividade política direta, procurava contrapor-se às tendências então predominantes no ambiente literário, que lhe parecia "alheio demais ao drama do nosso tempo". (CANDIDO, 2002, p. 41).

Lembremos que, ao iniciar o rodapé na Folha da manhã, Candido já havia passado pela guinada de politização da revista Clima, ocorrido em 1942, sobretudo por influência de Paulo Emílio Salles Gomes. Quando a revista apareceu, em maio de 1941, o que chamava atenção era o fato de manifestar o novo espírito universitário da Faculdade de Filosofia, Ciências e Letras, e não tanto as preocupações políticas, que pareciam ausentes das intenções iniciais daquele grupo de jovens intelectuais. O próprio Antonio Candido, em depoimento retrospectivo, identifica em Clima duas fases distintas, as quais compunham um trajeto em que a revista "começou apolítica, preocupada com o trabalho puramente intelectual, e foi se politizando lentamente, ficando cada vez mais radical, até uma atitude francamente empenhada". (CANDIDO, 1980a, p. 158). A trajetória de politização da revista correspondia também ao percurso paralelo do cidadão Antonio Candido que, acompanhando Paulo Emílio, passou a atuar em agrupamentos políticos sobretudo a partir de 1943 (ver CANDIDO, 1995). De 1941 a 1943, portanto, o jovem Antonio Candido havia passado por uma significativa iniciação na atividade política propriamente dita, o que decerto implicou também mais acentuada inclinação, na crítica de livros, para a atitude politicamente engajada.

Voltando ao primeiro número de Clima, é significativo que a revista trouxesse como artigo de abertura "A elegia de abril", de 
Mário de Andrade, convidado por Alfredo Mesquita, em nome do grupo, para iniciar a colaboração dos veteranos. O convite para que Mário participasse do número inaugural atestava $o$ vínculo que os novos intelectuais pretendiam estabelecer com a renovação cultural que vinha se processando desde os decênios anteriores e solicitava do então quase cinquentenário modernista uma reflexão sobre a inteligência brasileira atual. Em carta a Paulo Duarte, Mário de Andrade chegou a considerar a revista "um pouco pesada pra 'novos", ligando-se, nisso, à "tradição desta sublime burrice lenta e grave dos Paulistas" (DUARTE, 1985, p. 198 e 200); e embora valorizasse o incontestável ganho em conhecimento técnico propiciado pela Universidade - e também pelo Departamento Municipal de Cultura, em cuja direção ele mesmo havia se empenhado em anos anteriores (ver ANDRADE, 1993, p. 231) -, Mário sentia a insuficiência da inteligência técnica quando desvinculada de uma orientação (política) definida em face da vida.

Em "A elegia de abril" - confirmando o desejo, anunciado em carta a Moacir Werneck de Castro, de explicar melhor suas ideias (CASTRO, 1989, p. 172) -, Mário volta a discutir a questão da técnica, expandindo para os intelectuais o que havia dito a propósito dos artistas e, ao fazê-lo, apresenta com maior clareza as consequências éticas e políticas da aquisição de uma consciência técnica. A isso se associava uma avaliação da intelectualidade brasileira, e Mário decerto pressentia o rebuliço que seu ensaio poderia causar: "tudo quanto quero dizer é impublicável!", confidencia a Moacir Werneck, acrescentando que arranjaria um jeito de "dizer as coisas por imagens, e tomando exemplos do passado". (CASTRO, 1989, p. 172). Publicado o texto, e constatando o efeito produzido nos mais jovens, Mário explica a 
Otávio Dias Leite que "A elegia de abril" se dirigia sobretudo à geração de 1930 e, ato contínuo, acrescenta: “Agora, se qualquer um de vocês, honestamente, em pura consciência pessoal, achar que qualquer das censuras insertas na 'Elegia' também lhe cabe, não sei que culpa eu posso ter nisso!" (ANDRADE, 2006, p. 93; ver também ANDRADE, 1981, p. 89). O que importa salientar é que, na mesma carta a Otávio Dias Leite, Mário chama atenção para um aspecto do ensaio: depois de indicar o aumento de conhecimento técnico dos novos intelectuais, havia assinalado que "esse espírito universitário tinha obrigação de se definir diante da vida e que cultura não implica abstencionismo". (ANDRADE, 2006, p. 95).

No mesmo sentido se encaminha o trecho final de "O Movimento Modernista", do qual Candido extrai a frase que cita em "Ouverture": "O homem atravessa uma fase integralmente política da humanidade. Nunca jamais ele foi tão 'momentâneo' como agora. Os abstencionismos e os valores eternos podem ficar pra depois." (ANDRADE, 1974, p. 255). Em seguida, Mário avalia que os modernistas, a despeito dos avanços culturais que empreenderam, não participaram do "amilhoramento políticosocial do homem". Por isso, Mário encoraja a participação dos jovens intelectuais nas questões sociais do presente: "Façam ou se recusem a fazer arte, ciências, ofícios. Mas não fiquem apenas nisto, espiões da vida, camuflados em técnicos de vida, espiando a multidão passar. Marchem com as multidões." (ANDRADE, 1974, p. 255). Decerto a convocação de Mário de Andrade não implicava tanto que os intelectuais e os artistas atuassem diretamente na política, mas, sim, que assumissem sua responsabilidade social e evitassem a postura “"individualista' de recusar a vida", como afirma na carta a Otávio Dias Leite: "Não é possível mais barricadas? Revoluções? Pregações de comício? 
Escritos? Pois se trata então de tornar a vida tão virulentamente invivível que ela estoure de qualquer forma." (ANDRADE, 2006, p. 96).

No artigo inicial de Antonio Candido na Folha da manhã, a citação da conferência de Mário de Andrade assinalava que o jovem crítico havia entendido o recado que ele lançava à nova geração - recado que, em mais de uma ocasião, Mário lamentou não ter sido compreendido, como se verifica, por exemplo, em carta a Paulo Duarte: "O final [da conferência] bole, está claro, com a própria mocidade e esta não está querendo se incomodar. Então já inventaram um mito novo: 'O Mário foi muito injusto consigo mesmo' e ficam nisto. [...] Mas o que o final implica quem disse de se ao menos pensar sobre!" (DUARTE, 1985, p. 241).

3

Dois anos e meio depois do rodapé inaugural na Folha da manhã, Antonio Candido inicia sua colaboração no Diário de $\mathbf{S}$. Paulo, com o artigo "Começando", publicado em 20 de setembro de 1945 (CANDIDO, 2002). Para apresentar sua plataforma crítica, Candido esboça um balanço de sua atividade anterior e faz referência à mesma frase de "O Movimento Modernista", citada em "Ouverture", tomando-a como formulação pioneira da atitude participante, que buscava responder às necessidades da hora e que, em seguida, teria se espalhado na crítica brasileira, embora não por influência de Mário, nem nos termos em que este a propusera. Ao contrário do que talvez se esperasse, a atitude politicamente comprometida, que parecia disseminada, produziu um resultado que Candido considerava pernicioso para 
a crítica literária: o deslizamento da postura participante para a subordinação da crítica ao viés partidário, com "o aparecimento de pontos de vista políticos como critério de julgamento estético", ou, mais precisamente, "a passagem do critério mais vasto da ideologia para o sectarismo estreito dos partidos". (CANDIDO, 2002, p. 40). Com base nesse motivo, Candido pretende reorientar sua perspectiva crítica, considerando que "é chegado o momento de um ponto de vista mais literário e menos político - no tocante ao critério de interpretação -, e de um maior liberalismo - no que se refere ao julgamento". (CANDIDO, 2002, p. 41). Como observa Vinicius Dantas em nota ao texto, no momento em que o artigo foi escrito, um mês antes da queda de Vargas e com partidos de esquerda se organizando, abria-se um horizonte de democratização, contexto que ajudaria a explicar as novas formulações. Por fim, Candido salienta que "toda obra de valor é literária antes de ser sociológica ou política ou interessada ou desinteressada" (CANDIDO, 2002, p. 41) e declara que pretende, a partir dali, "tratar a literatura cada vez mais literariamente, reivindicando a sua autonomia e sua independência, acima das paixões nem sempre límpidas do momento". (CANDIDO, 2002, p. 43).

A um olhar distraído, poderia parecer que Candido adotava então uma postura quase oposta à que havia apresentado poucos anos antes, e consta mesmo que a citação do verso de Gautier - "Le buste survit à la cité" - que fechava o artigo, teria sido tomada por alguns como uma defesa da arte pela arte... Contudo, não só o respeito à integridade literária da obra já fazia parte dos princípios críticos expostos em "Ouverture”, como também a nova orientação não abdicava de tratar de questões políticas. Era apenas que Candido havia chegado a um refinamento de sua 
visão, agora distinguindo com maior nitidez questões estéticas e ideológicas para a avaliação crítica. Trata-se, com efeito, da primeira formulação mais completa de Candido quanto à distinção entre elementos estéticos e ideológicos que se encontram na configuração das obras, a partir da qual argumenta que, para a crítica, a definição do valor literário de uma obra não pode subordinar-se à natureza do conteúdo ideológico - mais tarde, Candido elaboraria essa distinção buscando discriminar e especificar as diferentes funções que a obra literária pode exercer (CANDIDO, 1980b).

Também a reorientação expressa em "Começando" havia se processado, ao menos em parte, com apoio em ideias de Mário de Andrade. Entre o final da colaboração para a Folha da manhã e o início do trabalho no Diário de S. Paulo, Candido participou do concurso à cátedra de Literatura Brasileira da Universidade de São Paulo e, em meados de 1944, chegou a pedir a Mário sugestões de assuntos para a escrita de uma tese para o concurso, que se realizou em julho de 1945 (CANDIDO, 1993b). Candido não se aventurou pelos temas propostos por Mário $^{2}$ e, como se sabe, preparou um estudo sobre Sílvio Romero, no qual, avaliando a obra do crítico sergipano, identifica as limitações e os perigos da abordagem estritamente sociológica e conclui pela necessidade de um ponto de vista crítico que respeite a integridade artística das obras; para formular esse resultado, Candido se vale de observações de Mário de Andrade, mas, desta vez, tomadas a "O artista e o artesão": "E se um artista é verdadeiramente artista, quero dizer, está consciente do seu destino e da missão que se deu para cumprir no mundo, ele

2 Iná Camargo Costa (2018) examinou o modo como as sugestões de Mário de Andrade foram assimiladas e desenvolvidas por Candido ao elaborar a Formação da literatura brasileira. 
chegará fatalmente àquela verdade de que, em arte, o que existe de principal é a obra de arte." (ANDRADE, 1975a, p. 11; CANDIDO, 1988, p. 103). Como se vê, a reorientação da atitude crítica, manifestada em "Começando", também implicava certa convergência com as ideias de Mário, embora pudesse parecerrepito, a um olhar superficial -, um recuo em relação à exigência de participação. Menos do que uma oscilação contraditória, de Mário ou de Candido, entre os polos da autonomia e da função social da literatura, a perspectiva que dava primazia ao artístico na obra de arte se apresentava a eles - decerto com diferenças em cada caso - como solução possível para o problema que então se apresentava como escolha entre alternativas mutuamente excludentes.

4

O problema do engajamento ou isenção do artista e do intelectual era uma questão central daqueles anos $1940 .{ }^{3}$ Reflexões sobre o tema podiam ser encontradas mesmo nos escritos de um crítico como Álvaro Lins, que, ao comentar o aparecimento de Clima, formulava a questão em termos dicotômicos:

Não sei, na verdade, o que será para a literatura e a arte uma traição maior: se o encerramento na "torre de marfim", a indiferença por toda atividade social e política, ou se a paixão partidária, tornando-se exclusivista, a personalidade do artista esgotandose toda nesta paixão, com prejuízo da sua obra, com prejuízo da sua arte. (LINS, 1941, p. 2).

3 Não comentarei aqui a voga do livro de Julien Benda, La trahison des clercs, que, no entanto, é um capítulo significativo da história cultural do período. 
Tanto Mário de Andrade quanto Antonio Candido identificavam em Álvaro Lins uma postura voltada para a permanência da obra fundada nos chamados "valores eternos" e para o não comprometimento do crítico com as questões políticas mais imediatas do momento. A propósito justamente desse artigo, Mário observa, em carta de 1943 ao próprio Lins, após a leitura da $2^{\mathrm{a}}$ série do Jornal de crítica: "E enfim na página importante que $\mathrm{V}$. escreveu sobre o $1^{\circ}$ número de Clima, você coloca em bases de uma verdadeira antinomia o cidadão e o artista. Consequência lógica de sua concepção da arte, isso me parece inaceitável." (ANDRADE, 1983a, p. 77). Mário resume a visão crítica de Álvaro Lins dizendo: "a Arte, pra V., se baseia no princípio de eternidade" (ANDRADE, 1983a, p. 78), e procura provocá-lo, argumentando que o ideal de crítica de Lins "leva à não-participação e à infecundidade" e, mais ainda, "leva ao atingimento de uma Verdade de lugar-comum, vulgar". (ANDRADE, 1983a, p. 80). A provocação que Mário expressa de maneira tão franca e direta, desejando que "maltratasse o seu espírito [de Lins]", tinha como finalidade incutir no crítico mais jovem um comprometimento maior com a função "pedagógica" de seu ofício: "Na verdade há um lado pedagógico na crítica, profundamente participante e fecundo, a que desde já sua atitude crítica está escapando muito." (ANDRADE, 1983a, p. 83). Tal atitude "pedagógica", de resto, havia sido um traço acentuado da crítica de livros que Mário praticou no Diário nacional entre 1939 e 1940; como o próprio Mário declara, seus artigos sobre literatura no jornal tinham um fundo comum, centrado no problema da técnica e da alta moralização do escritor através das exigências artísticas (ANDRADE, 1974). Insistindo que a técnica de artefazer é obrigação imprescindível do escritor, 
Mário dizia, em carta a Guilherme Figueiredo, ter renunciado ao ideal crítico de "Justiça imparcial e integral" em nome de uma "Injustiça utilitária", voltada para o desenvolvimento da consciência técnica na literatura nacional (ANDRADE, 1989).

De seu lado, ao comentar a $2^{\text {a }}$ série do Jornal de crítica do crítico pernambucano - por sinal, retomando o mesmo título, "Um crítico", usado por Mário de Andrade ao comentar o estudo de Lins sobre Eça de Queirós (ANDRADE, 1972) -, Candido reconhece nele "um interesse apaixonado pelo seu tempo e pelo seu semelhante", mas, assinala, Lins não permite que tal interesse estorve o ideal de isenção e equanimidade a que sua crítica aspira. Assim, Candido identifica certo tensionamento interno de Lins entre o desejo de afirmação da autonomia da literatura e as pressões da participação política:

Há certos momentos em que quase nos comovemos ante algumas das suas páginas, ao sentirmos a nobre tensão em que vive o seu espírito, defendendo ciosamente o justo equilíbrio e a imparcialidade, entre o impressionismo estético que ameaça os grandes individualistas e a solicitação da atividade no mundo, que arrasta o intelectual para o turbilhão dos acontecimentos e das paixões políticas. (CANDIDO, 1943b, p. 5).

No entanto, Candido avalia que, em última análise, para Álvaro Lins "o objeto da crítica [...] é a determinação, na obra literária, daquilo que é eterno, que transcende as contingências". (CANDIDO, 1943b, p. 5). Enquanto Mário de Andrade censurava Álvaro Lins sobretudo pela falta de uma atitude mais empenhada na construção da cultura nacional, que, a seu ver, se poderia alcançar exercendo a função pedagógica da crítica, o ponto de vista de Antonio Candido dirige-se, mais diretamente, às consequências políticas da crítica voltada aos "valores 
eternos" e à "aventura da personalidade", definindo uma postura que pretende colocar-se acima das solicitações do momento. ${ }^{4}$

Ainda a propósito de Álvaro Lins, mas desta vez comentando a $4^{\text {a }}$ série do Jornal de Crítica, em 1946, Candido observa que o volume apresenta maior presença de análise e discussão de ideias, sendo em menor número os estudos sobre ficção e poesia; e constata, no percurso de Lins, uma passagem "da atitude mais puramente estética para a atitude mais participante", mas "evitando, o mais possível, subordinar o significado específico da obra literária ao seu aproveitamento puramente ideológico". (CANDIDO, 1999, p. 19-20). O comentário à obra de Lins possibilita a Candido discutir as relações entre literatura e política e expressar sua própria visão a respeito da atividade crítica:

Acho que a literatura não tem obrigação de ser social nem os críticos o dever de julgar segundo padrões nãoliterários. Mas acho que, sobretudo em tempo como o nosso, o crítico só pode enriquecer a sua obra se tomar consciência dos problemas sociais e organizar o seu pensamento em relação a eles. Cada época tem problemas-chave, e os sociais, não se pode negar, ocupam a primeira plana em nossos dias. E a consciência é de tal modo solicitada por eles que se torna quase impossível não ter posição política definida, se não na militância, ao menos no campo teórico. (CANDIDO, 1999, p. 22).

A insistência de Mário de Andrade na necessidade, para o artista e o intelectual, de alcançar uma "técnica de pensamento"

4 Limito-me aqui ao comentário, a rigor parcial, das observações de Antonio Candido sobre Álvaro Lins em 1943. Para uma visão mais completa da trajetória intelectual do crítico pernambucano, que não deixou de ter momentos de participação política, ver o estudo de Adélia Bezerra de Meneses (1979). 
e, com ela, uma orientação definida diante da vida, envolvia o senso agudo das consequências que poderiam advir da falta de consciência sobre o ofício. Em mais de uma ocasião, Mário denuncia o perigo das posições que se alinham ao "desinteresse" da arte, sem que isso derive de uma atitude consciente frente à sociedade. Em carta de 1942 a Henriqueta Lisboa, Mário observa: “A arte não só 'tem de servir', o que já é doutrina e ideologia, mas serve mesmo, sempre e de qualquer forma. Quando não serve pra bem, serve mal e serve o mal, o erro." (ANDRADE, 2010, p. 223). De modo mais contundente, afirma em entrevista de 1944 a Francisco de Assis Barbosa:

Acho que o artista, mesmo que queira, jamais deverá fazer uma arte desinteressada. $\mathrm{O}$ artista pode pensar que não serve a ninguém, que só serve à Arte, digamos assim. Aí está o erro, a ilusão. No fundo, o artista está sendo um instrumento nas mãos dos poderosos. O pior é que o artista honesto, na sua ilusão de arte livre, não se dá conta de que está servindo de instrumento, muitas vezes para coisas terríveis. É o caso dos escritores apolíticos, que são servos inconscientes do fascismo, do capitalismo, do quinta-colunismo. (ANDRADE, 1983b, p. 103).

No mesmo sentido, em carta de 1943 a Fernando Sabino, Mário alerta o jovem escritor sobre as consequências de não transformar sua obra em elemento de seu combate:

Existem duas forças mais uma vez empenhadas em luta de vida ou morte, digamos mais ou menos eufemisticamente: a força da coletividade e a força da chefia. Ou você não-conformistamente se inclui na coletividade ou conformistamente se vende à chefia. [...] [N]ada impede, nada jamais não impedirá nunca que como obra-de-arte o seu livro seja uma obra vendida aos interesses da chefia, uma obra de função odiosamente capitalista, escravocrata e, meu Deus, até nazista. [...] 
Este é o princípio mesmo do nazismo, da sua mística e da sua prática. Um passo mais e o fracassado implora a descida dos céus de um Fuehrer! Porque o que há de mais pavoroso na fragilidade humana é que não tem só chefes escravocratas, o infamante é que há escravos escravocratas também. (ANDRADE, 2003, p.144-145).

Nessa passagem, Mário parece fazer menção à figura do fracassado, que, no artigo "O traço característico", de 1940, havia identificado como tipo literário recorrente no romance brasileiro daqueles anos - "não é o fracasso proveniente de forças em luta, mas a descrição do ser incapacitado para viver, o indivíduo desfibrado, incompetente, que não opõe força pessoal nenhuma, nenhum elemento de caráter, contra as forças da vida, mas antes se entrega sem quê nem porquê, à sua própria insolução” (ANDRADE, 1993, p. 181) - e que retoma, praticamente com os mesmos termos, em "A elegia de abril” (ANDRADE, 1974, p. 190), em que sugere uma relação entre o momento presente e "o convite à desistência e a noção do fracasso total" (ANDRADE, 1974, p. 191). Também aqui trata-se de uma consequência nefasta da falta de uma técnica de pensar e de uma orientação para a conduta, pois, como Mário sugere, seria a ausência de uma técnica de pensamento que faz os indivíduos desfibrados clamarem por um Messias-Führer. Além disso, note-se de passagem que o trecho da carta a Sabino talvez ajude a explicar a famosa - e enigmática - exclamação de Mário sobre Macunaíma, em carta a Álvaro Lins: "Pra esses moços, como pra os modernistas da minha geração, o Macunaíma é 'a projeção lírica do sentimento brasileiro, é a alma do Brasil virgem e desconhecida', que virgem nada! que desconhecida nada! Virgem, meu Deus! será muito mais um cão de nazista! Eu fracassei." (ANDRADE, 1983a, p. 66). 
Voltando ao nosso tema, digamos, para concluir provisoriamente estas anotações, que a controvérsia sobre arte "pura" e arte "interessada", que marcou a discussão sobre a cultura nos anos 1940, com as ressonâncias da polarização política do decênio anterior, viria ainda a se prolongar, com outra feição, após 1945, como atestam as disputas políticas em torno de entidades culturais como a Associação Brasileira de Escritores (ABDE).

Mais ainda, é possível dizer que, mesmo deixando de ser formulado nos termos de arte "pura" ou "interessada", o problema da função social da arte permaneceu como um eixo de reflexão teórica de Antonio Candido, que chegaria, no início dos anos 1960, a formulações teóricas por ele consideradas satisfatórias, constituindo-se como um caso à parte no movimento geral da crítica brasileira. Apenas para indicar a persistência da questão - e o que se mostra como um esforço contínuo de Candido de retomar, afinar e reelaborar a reflexão sobre o assunto -, lembremos que, por ocasião da $25^{\text {a }}$ reunião da SBPC, em 1973, a mesa "Literatura e sociedade", coordenada por ele, tomava como eixo da discussão o que o crítico chama de "pertinência da literatura" - entenda-se, pertinência social da literatura na atualidade-, e descreve como um desdobramento contemporâneo do já "superado debate entre 'arte pura' e 'arte interessada", acrescentando que, a esse núcleo, ligam-se "problemas como o da relação entre a literatura e as classes sociais, a literatura e a vida política". (CANDIDO, 1973, p. 14).

Assim, nos anos 1970, Candido reconhecia um fio de continuidade entre o velho debate que havia mobilizado os intelectuais brasileiros nos anos 1940 e as questões teóricas atuais, relacionadas ao significado social da arte e da literatura - 
questões que, como se sabe, constituíam a principal vertente da reflexão teórica e da prática crítica de Antonio Candido, o qual, a partir do fim dos anos 1950 e, sobretudo, início dos anos 1960, viria a desenvolver um conjunto de estudos que formulariam sua solução pessoal para o problema da polarização entre crítica estética e sociológica, tanto no âmbito teórico - em Literatura e sociedade (CANDIDO, 1980b) - quanto no da análise interpretativa - em O discurso e a cidade (CANDIDO, 1993a). A solução de Antonio Candido para os impasses da crítica literária, então dividida entre os formalismos e o sociologismo, implicava um ponto de vista que conjuga a preservação da autonomia da obra literária e a investigação de sua função e seu significado social. Quanto ao caráter histórico da própria solução de Antonio Candido, é um tema que exige estudo à parte, a ser desenvolvido em outra ocasião.

\section{Referências}

ANDRADE, Mário de. Aspectos da literatura brasileira. 5. ed. São Paulo: Martins, 1974.

ANDRADE, Mário de. O baile das quatro artes. 3. ed. São Paulo: Martins; Brasília: INL, 1975a.

ANDRADE, Mário de. O banquete. São Paulo: Duas Cidades, 1977.

ANDRADE, Mário de; SABINO, Fernando. Cartas a um jovem escritor e suas respostas. Rio de Janeiro: Record, 2003.

ANDRADE, Mário de. Cartas a Murilo Miranda (1934-1945). Rio de Janeiro: Nova Fronteira, 1981.

ANDRADE, Mário de. Cartas de Mário de Andrade a Álvaro Lins. Rio de Janeiro: José Olympio, 1983a. 
ANDRADE, Mário de. Correspondência Mário de Andrade \& Henriqueta Lisboa. Organização de Eneida Maria de Souza. São Paulo: Edusp/Petrópolis, 2010.

ANDRADE, Mário de. Cultura musical (Oração de paraninfo). In: ANDRADE, Mário de. Aspectos da música brasileira. 2. ed. São Paulo: Martins; Brasília: INL, 1975b, p. 233-247.

ANDRADE, Mário de. O empalhador de passarinho. 3. ed. São Paulo: Martins; Brasília: INL, 1972.

ANDRADE, Mário de. Entrevistas e depoimentos. Organização de Telê Porto Ancona Lopez. São Paulo: T.A. Queiroz, 1983b.

ANDRADE, Mário de. Esquerzo. Folha da manhã, São Paulo, 17 de junho de 1943, p. 9.

ANDRADE, Mário de. A lição do guru: cartas a Guilherme Figueiredo, 1937-1945. Rio de Janeiro: Civilização Brasileira, 1989.

ANDRADE, Mário de. Mário, Otávio: cartas de Mário de Andrade a Otávio Dias Leite (1936-1944). Organização de Marcos Antonio de Moraes. São Paulo: Imprensa Oficial do Estado de São Paulo/ Oficina do Livro Rubens Borba de Moraes/ IEB-USP, 2006.

ANDRADE, Mário de. 71 cartas de Mário de Andrade. Coligidas e anotadas por Lygia Fernandes. Rio de Janeiro: Liv. São José, 1963.

ANDRADE, Mário de. Vida literária. Organização de Sonia Sachs. São Paulo: Hucitec/ Edusp, 1993.

CANDIDO, Antonio. Artista e sociedade. Folha da manhã, São Paulo, 6 de junho de 1943a, p. 5.

CANDIDO, Antonio. Clima. In: CANDIDO, Antonio. Teresina etc. Rio de Janeiro: Paz e Terra, 1980a, p. 153-171.

CANDIDO, Antonio. Um crítico. Folha da manhã, São Paulo, 18 de julho de 1943b, p. 5. 
CANDIDO, Antonio. O discurso e a cidade. São Paulo: Duas Cidades, 1993a.

CANDIDO, Antonio. Jornada heroica. Folha da manhã, São Paulo, 30 de maio de 1943c, p. 5.

CANDIDO, Antonio. Literatura e sociedade. 6. ed. São Paulo: Nacional, 1980b.

CANDIDO, Antonio. O método crítico de Sílvio Romero. São Paulo: Edusp, 1988.

CANDIDO, Antonio. Paulo Emilio: a face política. In: CANDIDO, Antonio. Vários escritos. 3. ed., rev. e ampl. São Paulo: Duas Cidades, 1995, p. 337-358.

CANDIDO, Antonio. Recortes. São Paulo: Companhia das Letras, 1993b.

CANDIDO, Antonio. Sobre um crítico. Remate de males, Campinas, número especial Antonio Candido, p. 15-28, 1999.

CANDIDO, Antonio. Textos de intervenção. Organização de Vinicius Dantas. São Paulo: Duas Cidades/ Ed. 34, 2002.

CANDIDO, Antonio. Os rumos da literatura, Folha de S. Paulo, 5 de julho de 1973, p. 14.

CASTRO, Moacir Werneck de. Mário de Andrade: exílio no Rio. Rio de Janeiro: Rocco, 1989.

COLI, Jorge. Música final: Mário de Andrade e sua coluna jornalística Mundo musical. Campinas, SP: Ed. Unicamp, 1998. COSTA, Iná Camargo. Dois mestres do contra e a passagem ao terceiro. In: FONSECA, Maria Augusta; SCHWARZ, Roberto (Orgs.). Antonio Candido 100 anos. São Paulo: Ed. 34, 2018, p. 384-395.

DUARTE, Paulo. Mário de Andrade por ele mesmo. Prefácio de Antonio Candido. São Paulo: Hucite/Prefeitura do Município de São Paulo - Secretaria Municipal de Cultura, 1985. 
LAFETÁ, João Luiz. 1930: a crítica e o Modernismo. 2. ed. Prefácio de Antonio Candido. São Paulo: Duas Cidades / Ed. 34, 2000.

LINS, Álvaro. Sinais da nova geração. Correio da manhã, Rio de Janeiro, 19 de julho de 1941, p. 2.

MARTINS, Luís. Um livro e uma exposição. Folha da manhã, São Paulo, 17 de junho de 1943, p. 8.

MENESES, Adélia Bezerra de. A obra crítica de Álvaro Lins e sua função histórica. Petrópolis: Vozes, 1979.

MILLIET, Sérgio. O baile das quatro artes. A Manhã, Rio de Janeiro, 28 de maio de 1943a, segunda seção, p. 4.

MILLIET, Sérgio. Fui bulir em vespeira. O Estado de S. Paulo, 18 de junho de 1943b, p. 3. 